Article

\title{
Detailed Sponge City Planning Based on Hierarchical Fuzzy Decision-Making: A Case Study on Yangchen Lake
}

\author{
Junyu Zhang ${ }^{1,2}$, Dafang Fu ${ }^{1,2}$, Yajun Wang ${ }^{2,3}$ and Rajendra Prasad Singh ${ }^{1,2, *}$ \\ 1 Joint Research Centre for Water Sensitive Cities, Southeast University-Monash University Joint Graduate \\ School (Suzhou), Southeast University, Suzhou 215123, China; junyu.zhang@monash.edu (J.Z.); \\ fdf@seu.edu.cn (D.F.) \\ 2 Department of Civil Engineering, Southeast University, \#2Sipailou, Nanjing 210096, China; \\ 230149631@seu.edu.cn \\ 3 School of Civil Engineering, Lanzhou University of Technology, 287 Langongping, Lanzhou 730050, China \\ * Correspondence: rajupsc@seu.edu.cn
}

Received: 16 October 2017; Accepted: 17 November 2017; Published: 20 November 2017

\begin{abstract}
We proposed a Hierarchical Fuzzy Inference System (HFIS) framework to offer better decision supports with fewer user-defined data (uncertainty). The framework consists two parts: a fuzzified Geographic Information System (GIS) and a HFIS system. The former provides comprehensive information on the criterion unit and the latter helps in making more robust decisions. The HFIS and the traditional Multi-Criteria Decision Making (MCDM) method were applied to a case study and compared. The fuzzified GIS maps maintained a majority of the dominant characteristics of the criterion unit but also revealed some non-significant information according to the surrounding environment. The urban planning map generated by the two methods shares similar strategy choices (6\% difference), while the spatial distribution of strategies shares $69.7 \%$ in common. The HFIS required fewer subjective decisions than the MCDM (34 user-defined decision rules vs. 141 manual evaluations).
\end{abstract}

Keywords: Sponge City; urban planning; fuzzy logic; GIS; flooding

\section{Introduction}

With the tremendous development in China over the past few decades, various problems resulting from rapid urbanization, population growth, and climate change have emerged. The failure of water drainage systems is one of the most common. Due to a low design capacity, a lack of maintenance, and a reduction in natural buffering areas, flooding and waterlogging caused by this failure are in turn causing huge losses in terms of both property and human lives.

The Sponge City concept was proposed in 2012 in China during the Low-Carbon Urban Development and Technology Forum to address the conflict between development and resilience cities face [1]. Similar concepts in urban planning, such as Best Management Practices [2], Low Impact Development [3], and Water Sensitive Urban Design [4] have been successfully practiced, but there is still a long way to go to adapt, improve, and develop proper techniques, strategies, and planning methods to meet local conditions and needs in China.

Followed by a barrage of government-issued policies, several cities in China with different population densities, spatial scales, and climate conditions are currently sponsored to explore the applicative national strategy and practice of Sponge City by the 2020s. Meanwhile, current Sponge City designs and construction plans do not satisfy our expectations [1]. To achieve better performance and more cost-efficiency, it is urged that a proper decision-making method be employed in the planning process. Although many novel, powerful, and accurate models and tools to support decision making 
have emerged in recent years [5-9], most of them have been developed and used by experienced researchers or developers. It is almost impossible for lay designers and decision makers to correctly and easily apply those tools to their work.

Some widely used methods are usually simple and straightforward. One of the most commonly used decision support method is Multi-Criteria Decision Making (MCDM), which combines quantitative and qualitative criteria to form a single index of evaluation. Implemented in a Geographic Information System(GIS) environment, MCDM has been applied in various studies in such areas as resource management [10], urban planning [11-14], and vulnerability assessment [15-18] over the last few decades. Such spatial-based MCDM involves a set of geographically defined basic units (e.g., polygons, or cells), and a set of evaluation criteria represented as map layers [11]. The criterion maps rank each unit with an overall score according to the attribute values and criteria weights using different analyzing approaches (e.g., Boolean overlay, weighted linear combination, and ordered weighted average) [13]. The Analytical Hierarchy Procedure (AHP) [19] is a method widely used for ranking multi-criteria weights. It calculates the weighting factors using a pairwise comparison matrix where all relevant criteria are compared against each other with reproducible preference factors.

Another decision support method is Fuzzy Decision Making, which is a mathematical method for supporting decision making under uncertain situations with limited information [20]. It consists in an inference structure that enables appropriate human reasoning capabilities. It has been widely applied in studies relating to vulnerability assessment $[15,17,21-25]$ and urban planning [26-30]. The approach sets up a fuzzy inference system (FIS), which consists in user-defined membership functions and decision rules [20]. The value for each criterion is first divided into classes/words, and a membership function is used to identify the range of each class/word. Each class has overlay parts with adjacent classes to represent the fuzziness. The decision rules represent the ambiguous designing principle of the planner (e.g., if the imperviousness is low and the pollution productivity is high, then the vulnerability is high). The criterion maps rank each unit by allocating their input distribution in the membership function and finding out their output distribution according to the rule set and rule strength, which is called the Mamdani method [31].

Realistically, the application of such methods requires a comprehensive understanding of the planning process as well as sufficient data. On one hand, the more data we have, the more comprehensive we can understand the situation and make more reliable decisions. On the other hand, the more data we are dealing with, the more subjective pairwise comparison matrixes (e.g., MCDM) or decision rules (e.g., FIS) we need to establish and therefore the more uncertain we are of the decisions. Nevertheless, the above method usually evaluates criteria units individually (especially polygons) and disregards the surrounding features.

In this study, we developed an easily applicable decision-making framework that applies a hierarchical FIS system [24] on a fuzzified GIS system, in order to offer better decision supports with fewer user-defined data. The hierarchical FIS system aims to reduce the subjective judgement from planners, minimizing uncertainty in the system. The fuzzified GIS system provides comprehensive information on the surrounding environment to support better decisions. The developed framework and the traditional MCDM method were applied on a planning program at Yangchen Lake Resort, Suzhou, Jiangsu, China. The results of both methods were compared so that the pros and cons for each approach could be analyzed.

\section{Methods and Data Description}

\subsection{Study Description}

The $61.7 \mathrm{~km}^{2}$ Yangchen lake resort consists of two peninsulas, over which more than 100 inner rivers are spread (see Figure 1). About $3.5 \mathrm{~km}^{2}$ of land area is used for various kinds of farming activities (rice, vegetable, fruit, and fishery) and $5 \mathrm{~km}^{2}$ is used for public landscapes and parks. A new town is gradually developing at the upper end of the left peninsula. 
Due to pollution from farming and a lack of maintenance, more than one-third of the inner rivers are blocked. The performance of the drainage system is poor in the town area as the design can be traced back for decades.

The aim of the design is to offer decision support for Sponge City planning (where to introduce new techniques, cost-efficiency on adapting strategies, etc.), such that the retrofit impact in the area of the resort is minimized and the hydrology performance of the resort's water system is more cost-efficient.

There are four candidate strategies: business as usual (BAU), rain tank or green roof (small scale system), rain garden or bioretention cell (large scale system), and re-planning.

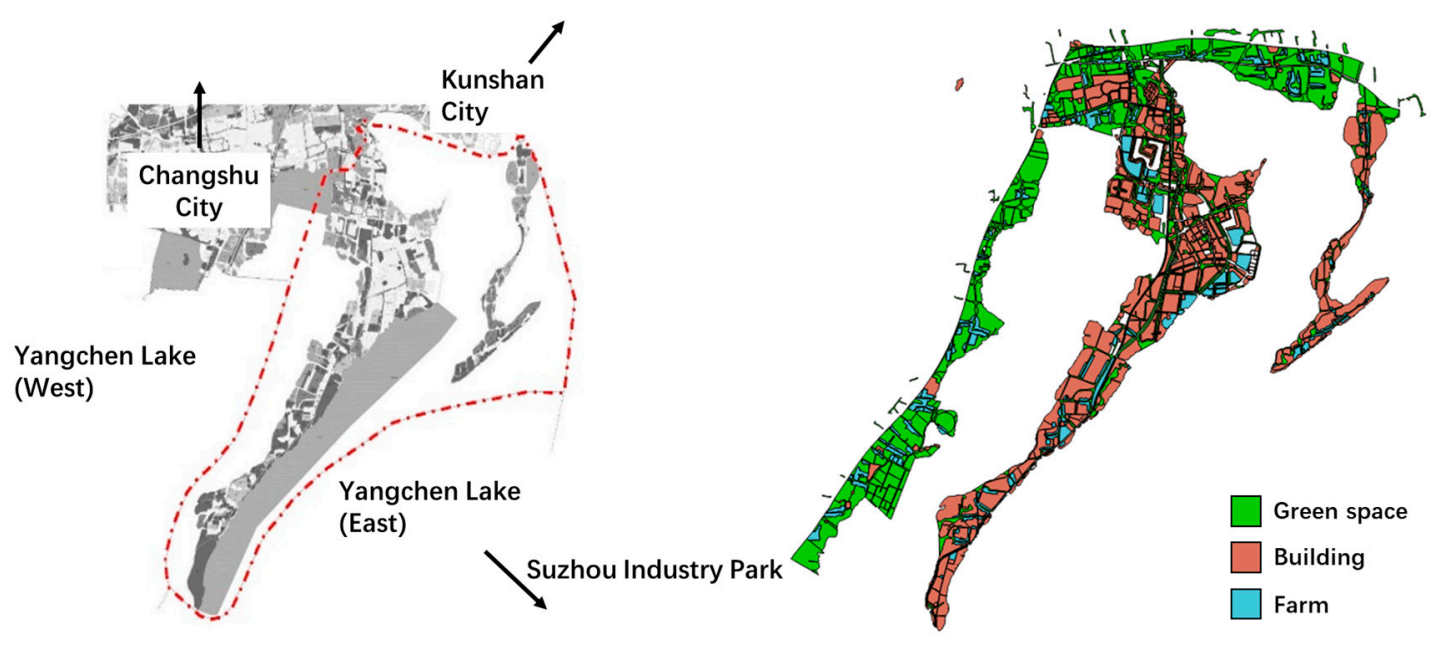

Figure 1. Case Study: Yangchen lake resort.

\subsection{Data Collection and Criteria Selection}

On the basis of a dwg map from the stakeholders, field investigations were carried out to gather information about land use, the source of pollution, and the environmental status on site. The dwg file was then transformed into a GIS map via ArcGIS, and these data were inputted into each polygon. Together with experienced designers, major criteria pertaining to permeability, pollution productivity, loss from flooding, and retrofit cost, were identified. Due to limitations in data accessibility, the four features are represented by 0,1 , and 2 (indicating low, medium, and high) for every polygon according to the designers' experience (see Table 1).

Table 1. Geographic Information System (GIS) features for the resort.

\begin{tabular}{ccccc}
\hline Land Use & Permeability & Pollutant Productivity & Loss from Flooding & Retrofit Cost \\
\hline Farm & 1 & 2 & 1 & 1 \\
Building & 0 & 1 & 2 & 2 \\
Green space & 2 & 0 & 0 & 0 \\
\hline
\end{tabular}

Notes: 0: Low; 1: Medium; 2: High.

\subsection{Methodology}

We applied MCDM and HFIS in this case study according the following procedures (see Figure 2).

\subsubsection{Multi-Criteria Decision Making with an Analytical Hierarchy Procedure}

The MCDM process requires decision makers to rank the criteria based on pairwise comparisons. In this study, these comparisons were obtained from a survey of 25 experts that included members of the urban planning institute as well as academic experts specialized in urban planning. Each participant 
was asked to rank the criteria and class by referring to a numerical scale of $1-9$, with a score of 1 representing indifference between the two criteria and 9 indicating a great amount of concern [13].

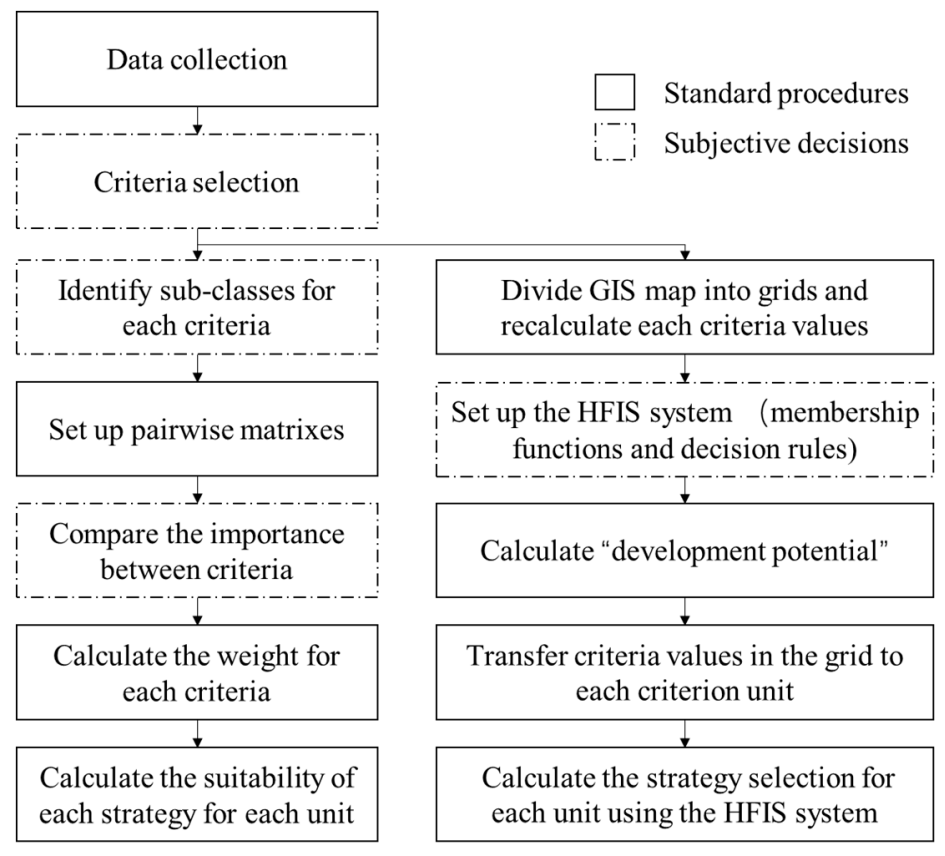

MCDM

\section{HIFS}

Figure 2. Multi-Criteria Decision Making (MCDM) and Hierarchical Fuzzy Inference System (HFIS) flow chart.

The final 25 pairwise comparisons matrixes were establish based on the mean value of all survey results. The weight for each criteria, class, and strategy were then calculated using the AHP method (see Table 2). The consistency ratio (CR) was calculated to evaluate the consistency of pairwise comparisons. A standard CR threshold value of 0.10 was applied. The pairwise comparisons in this study were consistent with a consistency ratio (CR) of $<0.10$.

Table 2. Criteria tree and Analytical Hierarchy Procedure (AHP) results.

\begin{tabular}{|c|c|c|c|c|c|c|c|c|c|}
\hline \multirow{2}{*}{ Goal } & \multirow{2}{*}{ Weight } & \multirow{2}{*}{ Criteria } & \multirow{2}{*}{ Weight } & \multirow{2}{*}{ Class } & \multirow{2}{*}{ Weight } & \multicolumn{4}{|c|}{ Strategy Weight } \\
\hline & & & & & & $\begin{array}{l}\text { Business } \\
\text { as Usual }\end{array}$ & $\begin{array}{c}\text { Raintank } \\
\text { Green Roof }\end{array}$ & $\begin{array}{l}\text { Rain Garden } \\
\text { Bioretention }\end{array}$ & Re-Planning \\
\hline \multirow{18}{*}{ Development } & \multirow{18}{*}{1.0000} & \multirow{3}{*}{ Permea-bility } & \multirow{3}{*}{0.0553} & High & 0.0754 & 0.6692 & 0.1155 & 0.1155 & 0.0998 \\
\hline & & & & Medium & 0.2290 & 0.2500 & 0.2500 & 0.2500 & 0.2500 \\
\hline & & & & Low & 0.6955 & 0.0871 & 0.3854 & 0.3854 & 0.1422 \\
\hline & & \multirow{3}{*}{ Land use } & \multirow{3}{*}{0.0649} & Farm & 0.6955 & 0.0886 & 0.0952 & 0.5513 & 0.2649 \\
\hline & & & & Building & 0.2290 & 0.3812 & 0.4331 & 0.1030 & 0.0828 \\
\hline & & & & Park & 0.0754 & 0.6201 & 0.0708 & 0.2166 & 0.0925 \\
\hline & & \multirow{3}{*}{ Area (ha) } & \multirow{3}{*}{0.0401} & $1.19-45$ & 0.1140 & 0.3000 & 0.3000 & 0.3000 & 0.1000 \\
\hline & & & & $0.25-1.19$ & 0.4054 & 0.2500 & 0.2500 & 0.2500 & 0.2500 \\
\hline & & & & $0-0.25$ & 0.4806 & 0.2857 & 0.2857 & 0.2857 & 0.1429 \\
\hline & & \multirow{3}{*}{ Flood loss } & \multirow{3}{*}{0.2994} & High & 0.7514 & 0.0445 & 0.1723 & 0.1958 & 0.5874 \\
\hline & & & & Medium & 0.1782 & 0.0813 & 0.3598 & 0.3598 & 0.1991 \\
\hline & & & & Low & 0.0704 & 0.3000 & 0.3000 & 0.3000 & 0.1000 \\
\hline & & \multirow{3}{*}{ Retrofit cost } & \multirow{3}{*}{0.3286} & High & 0.0658 & 0.4167 & 0.0833 & 0.0833 & 0.4167 \\
\hline & & & & Medium & 0.2172 & 0.3000 & 0.3000 & 0.3000 & 0.1000 \\
\hline & & & & Low & 0.7171 & 0.3125 & 0.3125 & 0.3125 & 0.0625 \\
\hline & & \multirow{3}{*}{ Pollution } & \multirow{3}{*}{0.2117} & High & 0.7429 & 0.0457 & 0.1451 & 0.3494 & 0.4598 \\
\hline & & & & Medium & 0.1939 & 0.0871 & 0.3854 & 0.3854 & 0.1422 \\
\hline & & & & Low & 0.0633 & 0.3313 & 0.2916 & 0.2916 & 0.0855 \\
\hline
\end{tabular}


After the factors, their weights, and all constraints in the decision tree were established for each strategy, the suitability of each strategy was calculated for each unit in the criterion map according to its criteria value (Suitability $=$ Criteria Weight $\times$ Class Weight $\times$ Strategy Weight). The sponge urban planning map was generated by selecting the most suitable strategy for each unit.

\subsubsection{Hierarchical Fuzzy Inference System (HFIS) Decision Making}

\section{Step 1 "Fuzzification" of GIS Maps}

As discussed before, a major goal of this framework is to provide comprehensive information from the surrounding environment for each criteria unit. In this study, we first divided the resort into $100 \mathrm{~m}$ $\times 100 \mathrm{~m}$ (1 ha) grids. The size of the grids was determined considering the mid-value ( $0.55 \mathrm{ha})$ and distribution $(<1$ ha: $63 \%)$ of the polygon area in the GIS map. Such grids offered an adequate capacity of embracing characteristics of multiple polygons. Permeability, pollutant productivity, and loss from flooding was calculated for each grid according to the corresponding value in the polygon they intersected (Equation (1)).

$$
I_{B, j}=\sum I_{A, j} \frac{a_{i}^{\prime}}{A_{i}^{\prime}}
$$

where

$I_{B, j}$ is the criteria value of grid $j$;

$I_{A, i}$ is the value of the corresponding criteria in polygon $i$;

$a_{i}^{\prime}$ is the intersect area of grid $j$ and polygon $i$;

$A_{i}^{\prime}$ is the area of polygon $i$.

\section{Step 2 Fuzzy Analysis}

A Matlab (R2017a) toolbox, the Fuzzy Logic Designer, was used to set up the FIS based on the result from Step 1. The Gaussian Membership Functions are adopted for the following criteria to allow better deviation to these fuzzified values (see Figure 3). "Permeability" and "pollutant productivity" were first analyzed to evaluate the "vulnerability" of each grid. Together with the "loss from flooding", the "vulnerability" went through the FIS again to calculate the "develop potential". The advantage of using a two-layer fuzzy process instead of dealing with three parameters at a time (using permeability, pollutant productivity, and loss for flooding to directly analyze develop potential) is that the former requires fewer inputs. The two-layer fuzzy module requires two rule sets with 25 rules each (for two parameters with 5 value ranges, the minimum amount of rules will be $5 \times 5$ ), while the one-layer module would need a set of 125 rules. If fewer rules are designed, more uncertainty will be reduced from the cognitive limitation.

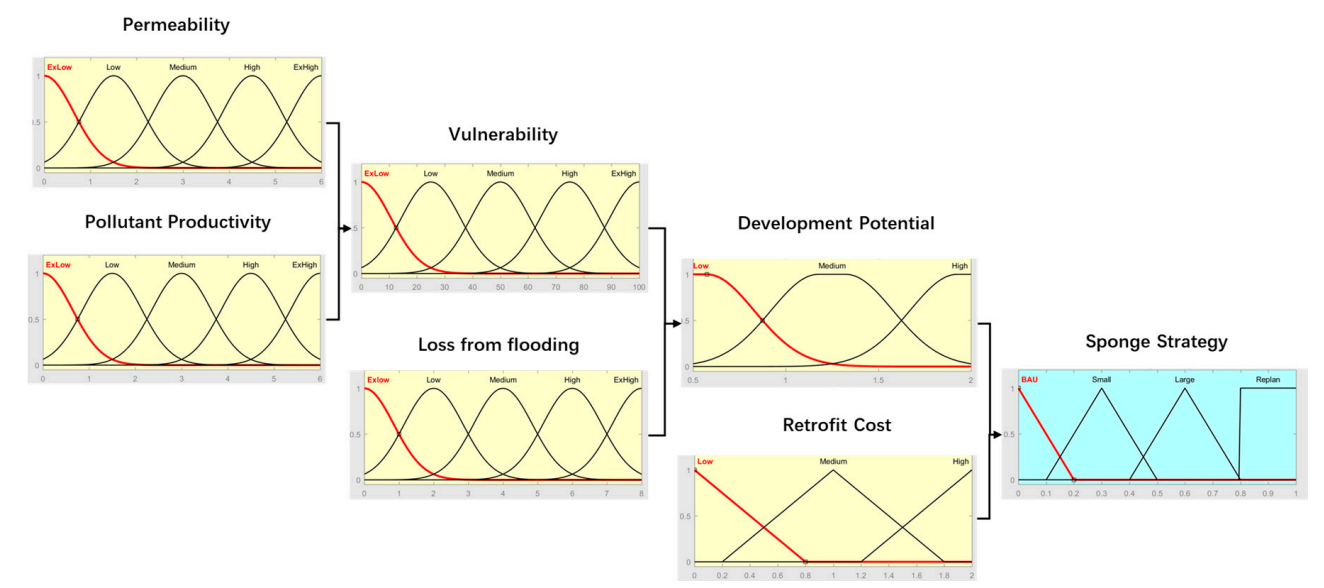

Figure 3. Designed membership functions of the hierarchical fuzzy inference system (FIS). 
Step 3 "Defuzzification" of GIS Maps and Strategy Selection

In this stage, information is translated from a grid map to an original GIS map through Equations (2) and (3) so that the need for each land can be understood.

$$
\begin{gathered}
D_{A, i}=\sum D_{B, j} \frac{a_{j}^{\prime}}{A_{i}} \\
A_{i}=\sum a_{j}^{\prime}
\end{gathered}
$$

where

$D_{A, i}$ is the development potential of polygon $i$;

$D_{B, i}$ is the development potential of grid $j$;

$a_{j}^{\prime}$ is the intersecting area of grid $j$ and polygon $i$;

$A_{i}$ is the area of polygon $i$.

A third fuzzy process was conducted with the development potential and retrofit cost, in the same way as Step 2, to determine the strategy to be chosen (business as usual, rainwater tank, rain garden, or re-planning). The Trapezoidal Membership Function are adopted in this step to allow crisper decision choices (see Figure 3). The sponge urban design map was then worked out to visualize the strategy choice.

\section{Results and Discussion}

\subsection{Fuzzified GIS Map}

Compared to the original GIS maps, the fuzzified maps present the same or less intensive criteria values in most areas (see Figure 4). This indicates that the fuzzification process under this gridding scale can maintain the dominant characteristics of the polygons while considering the surrounding environment and can make reasonable adjustments. Notably, the highlighted Areas A and B initially had the same attribute values but ended up with different fuzzified values. The reason for this difference results from the more intensive land use in Area A. Despite the same land use type, there were more scattered green spaces and inner rivers within Area B. The fuzzified GIS map proved to be efficient in revealing this non-significant information, which influences the final decision.
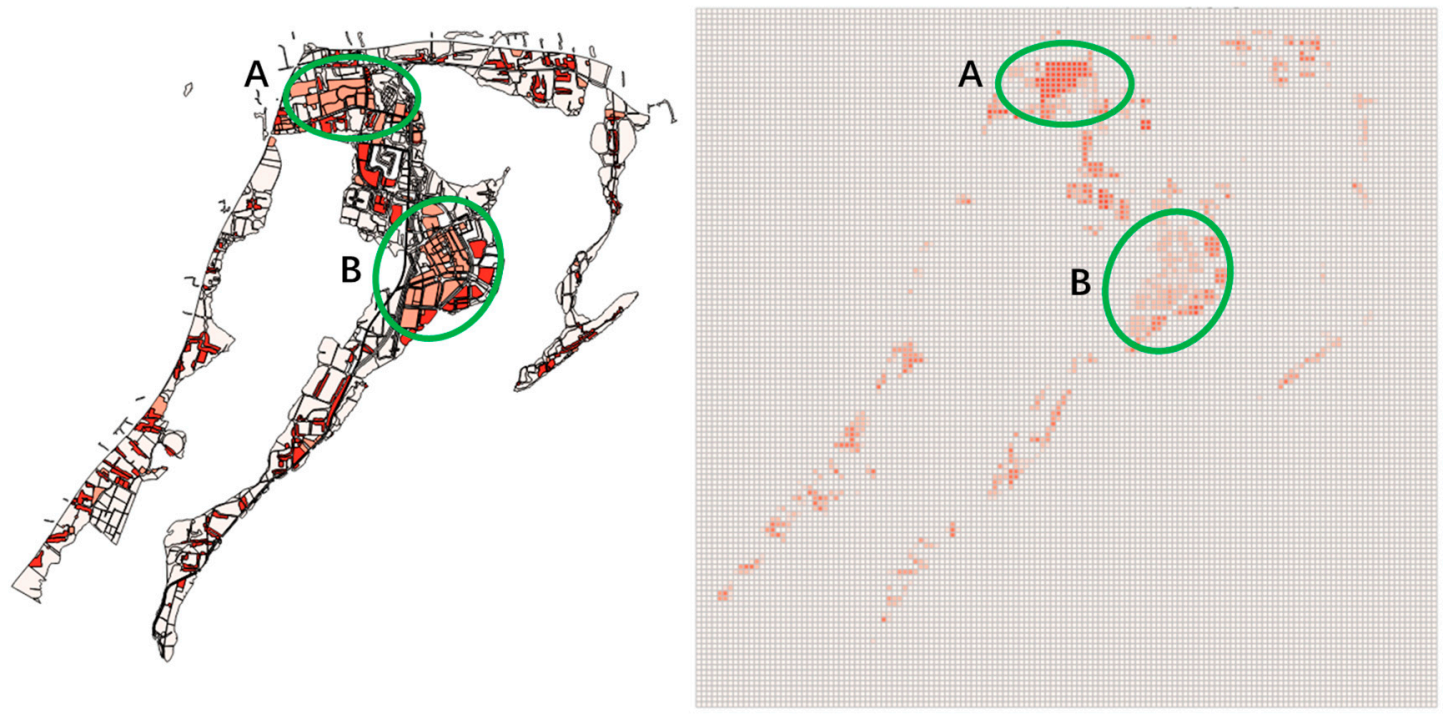

Figure 4. Example of a fuzzified GIS map (pollutant productivity). 


\subsection{Sponge Urban Plan for Yangchen Lake Resort}

The result of the sponge urban planning map is presented in Figure 5. This map suggests that $55.6 \%$ (MDCM) or $49.7 \%$ (HFIS) of the resort can undertake the business as usual strategy. These areas include the majority of the west and north green spaces of the resort and the residential areas in the middle peninsula. These areas have relatively good permeability (by themselves or by adjacent to the lake), moderate pollutant productivity, or low loss from flood.

It is also suggested that $22.7 \%$ (MDCM) or $28.7 \%$ (HFIS) of the resort apply rain water tanks or green roofs. These areas consist of high-density buildings whose runoff contributes to the pollution in adjacent areas (such as farming).

The map further suggests that $21.7 \%$ (MDCM) or $21.6 \%$ (HFIS) of the resort have rain gardens or bioretention cells implemented. Most of these would be located in areas related to farming. The pollution from fish farming is extremely high, so it is advisable to take advantage of the reserved land and to construct a large-scale rain garden to hold and treat the runoff from the farming area.
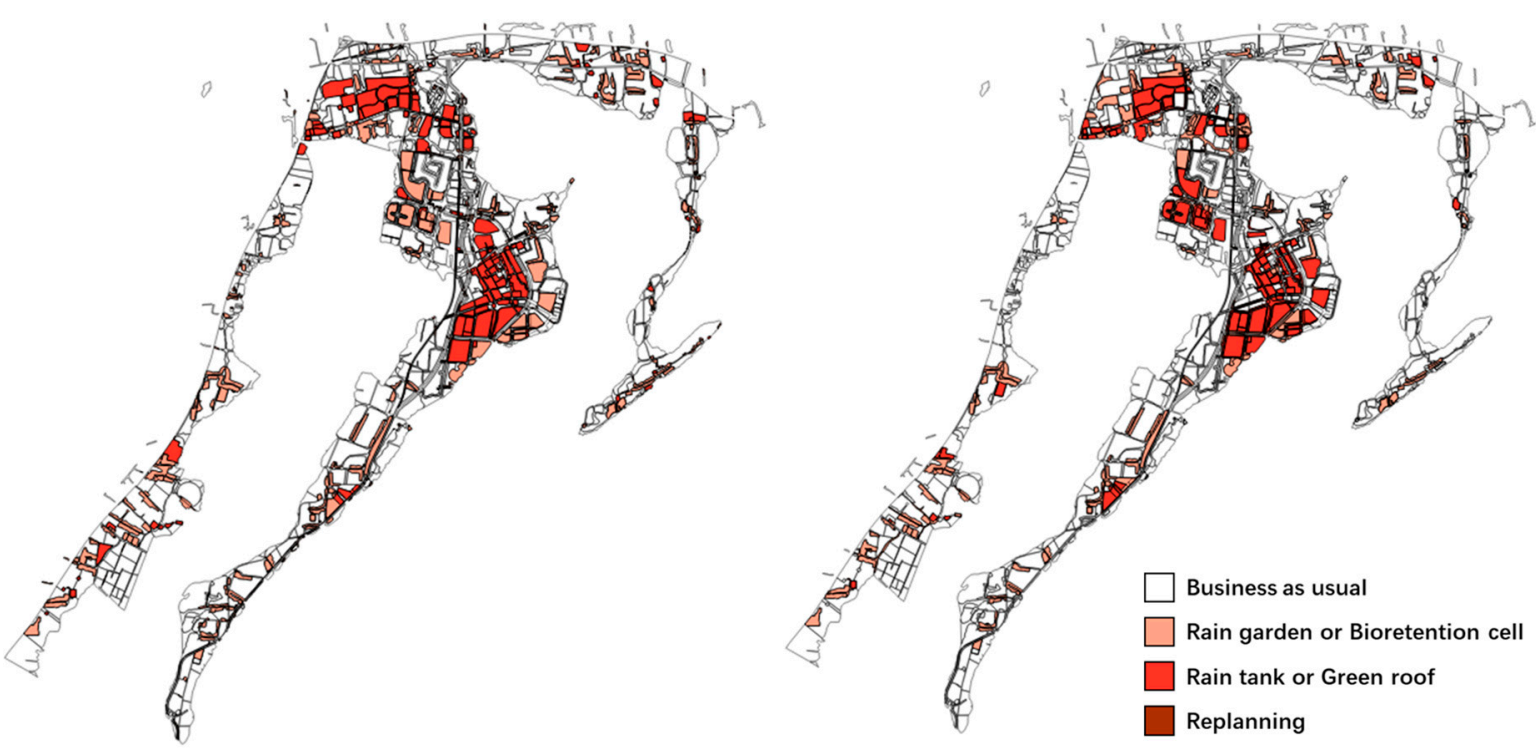

Figure 5. Sponge urban planning maps for MCDM (left) and hierarchical FIS (right).

\subsection{Comparison of MCDM and HFIS}

In this study, the two methods both require selection and identification of criteria and their classes' ranges. To generate a planning map, MCDM methods required the planners to fulfill 25 pairwise comparison matrixes, which consist of 141 manual evaluations for deciding the importance between two criteria to their upper level criteria. The three-level HFIS required to design 34 decision rules to determine which strategy was preferred under certain conditions.

As discussed in Section 3.2, the two methods produced similar results regarding the total area of each strategy (see Table 3). The HFIS suggested a bit more rain tank/green roof uptake instead of business as usual (6\%). In regard to the spatial distribution of the strategies, $69.7 \%$ of the resort planning generated by the HFIS uses the exact same strategy as that used by MCDM. Moreover, the two methods suggested different strategies (other than business as usual) with respect to $3.26 \%$ of the planning area. 
Table 3. Comparison of the results from HFIS and MCDM.

\begin{tabular}{cccc}
\hline & Comparison criteria & HFIS & MCDM \\
\hline \multirow{2}{*}{ Strategy Choice } & Business as ususal & $49.7 \%$ & $55.6 \%$ \\
& rain water tanks or green roofs & $28.7 \%$ & $22.7 \%$ \\
& the rain garden or bioretention cells & $21.6 \%$ & $21.7 \%$ \\
\hline Overlay area of choosing same strategy (other than BAU) & \multicolumn{2}{c}{$69.7 \%$} \\
\hline User-defined decisions & 34 & 141 \\
\hline
\end{tabular}

\section{Conclusions}

In this study, a decision-making framework was developed and verified to offer better decision support with fewer user-defined data (to reduce uncertainty). The framework consists of two parts: a fuzzified GIS system and a hierarchical FIS system. The developed framework and the traditional MCDM method were applied on a planning program at Yangchen Lake Resort, Suzhou, Jiangsu, China.

In this study, with the grid size we selected (1 ha), the fuzzified GIS maps maintained a majority of the dominant characteristics of the polygons. The process, by considering the surrounding environment and making reasonable adjustments, also proved to be efficient in revealing non-significant information.

The sponge urban planning map generated by the two methods shares similar strategy choices: BAU: $55.6 \%$ (MDCM) or $49.7 \%$ (HFIS); rain tanks or green roofs: $22.7 \%$ (MDCM) or $28.7 \%$ (HFIS); rain gardens or bioretention cells: $21.7 \%$ (MDCM) or $21.6 \%$ (HFIS). The spatial distribution of strategies (other than BAU) have $69.7 \%$ in common.

Regarding the user-defined data, the two methods both require the selection and identification of criteria and their classes' ranges. In this study, the MCDM methods required 25 pairwise comparison matrixes, which consist of 141 manual evaluations to decide the importance between the two criteria. The HFIS required the design of 34 decision rules to determine which strategy was preferred under certain conditions.

Acknowledgments: The research is co-funded by the National Key Technologies R\&D Program (No. 2015BAL02B05) and the Priority Academic Program Development of the Jiangsu Higher Education Institution. Thanks to Professor Dafang Fu for the creative leadership and for motivating us to finish the research. Thanks also to Yajun Wang, Shibo Hao, Yangke Li, Hong Zhang, Gongjun Huang, Zhongshuai Jiang, Kun Wei, Jinhui Yang, and Zhongxiang Zhang, who dedicate their time and passion in these two difficult field investigations. Thanks to Chenli $\mathrm{Wu}$, who encouraged us to finish the work.

Author Contributions: Junyu Zhang and Dafang Fu conceived and designed the experiments. Junyu Zhang and Yajun Wang conducted the data collection and performed the experiment; Junyu Zhang and Rajendra Prasad Singh analyzed the data and wrote the paper.

Conflicts of Interest: The authors declare no conflict of interest.

\section{References}

1. Xia, J.; Zhang, Y.; Xiong, L.; He, S.; Wang, L.; Yu, Z. Opportunities and challenges of the Sponge City construction related to urban water issues in China. Sci. China Earth Sci. 2017, 60, 652-658. [CrossRef]

2. Urbonas, B.; Stahre, P. Stormwater: Best Management Practices and Detention for Water Quality, Drainage, and CSO Management; Prentice Hall: Upper Saddle River, NJ, USA, 1993.

3. Fairlie, S. Low Impact Development: Planning and People in a Sustainable Countryside; Jon Carpenter Chipping Norton: Chipping Norton, UK, 1996.

4. Wong, T.H.; Brown, R.R. The water sensitive city: Principles for practice. Water Sci. Technol. 2009, 60, 673-682. [CrossRef] [PubMed]

5. Albano, R.; Mancusi, L.; Abbate, A. Improving flood risk analysis for effectively supporting the implementation of flood risk management plans: The case study of "Serio" Valley. Environ. Sci. Policy 2017, 75, 158-172. [CrossRef] 
6. Inam, A.; Adamowski, J.; Halbe, J.; Malard, J.; Albano, R.; Prasher, S. Coupling of a distributed stakeholder-built system dynamics socio-economic model with SAHYSMOD for sustainable soil salinity management part 1: Model development. J. Hydrol. 2017, 551. [CrossRef]

7. Urich, C.; Sitzenfrei, R.; Kleidorfer, M.; Bach, P.M.; McCarthy, D.T.; Deletic, A.; Rauch, W. Evolution of urban drainage networks in DAnCE4Water. In Proceedings of the 9th International Conference on Urban Drainage Modelling, Belgrade, Serbia, 4-6 September 2012.

8. Ferguson, B.C.; Brown, R.R.; Frantzeskaki, N.; de Haan, F.J.; Deletic, A. The enabling institutional context for integrated water management: Lessons from Melbourne. Water Res. 2013, 47, 7300-7314. [CrossRef] [PubMed]

9. Hall, J.W.; Lempert, R.J.; Keller, K.; Hackbarth, A.; Mijere, C.; McInerney, D.J. Robust climate policies under uncertainty: A comparison of robust decision making and info-gap methods. Risk Anal. 2012, 32, 1657-1672. [CrossRef] [PubMed]

10. Chang, N.B.; Qi, C.; Yang, Y.J. Optimal expansion of a drinking water infrastructure system with respect to carbon footprint, cost-effectiveness and water demand. J. Environ. Manag. 2012, 110, 194-206. [CrossRef] [PubMed]

11. Chen, Y.; Paydar, Z. Evaluation of potential irrigation expansion using a spatial fuzzy multi-criteria decision framework. Environ. Model. Softw. 2012, 38, 147-157. [CrossRef]

12. Jeong, J.S.; García-Moruno, L.; Hernández-Blanco, J. A site planning approach for rural buildings into a landscape using a spatial multi-criteria decision analysis methodology. Land Use Policy 2013, 32, $108-118$. [CrossRef]

13. Rahman, R.; Saha, S.K. Remote sensing, spatial multi criteria evaluation (SMCE) and analytical hierarchy process (AHP) in optimal cropping pattern planning for a flood prone area. J. Spat. Sci. 2008, 53, 161-177. [CrossRef]

14. Van Niekerk, A.; du Plessis, D.; Boonzaaier, I.; Spocter, M.; Ferreira, S.; Loots, L.; Donaldson, R. Development of a multi-criteria spatial planning support system for growth potential modelling in the Western Cape, South Africa. Land Use Policy 2016, 50, 179-193. [CrossRef]

15. Araya-Munoz, D.; Metzger, M.J.; Stuart, N.; Wilson, A.M.W.; Carvajal, D. A spatial fuzzy logic approach to urban multi-hazard impact assessment in Concepcion, Chile. Sci. Total Environ. 2017, 576, 508-519. [CrossRef] [PubMed]

16. Pourghasemi, H.R.; Moradi, H.R.; Fatemi Aghda, S.M.; Gokceoglu, C.; Pradhan, B. GIS-based landslide susceptibility mapping with probabilistic likelihood ratio and spatial multi-criteria evaluation models (North of Tehran, Iran). Arab. J. Geosci. 2013, 7, 1857-1878. [CrossRef]

17. Radmehr, A.; Araghinejad, S. Flood vulnerability analysis by fuzzy spatial multi criteria decision making. Water Resour. Manag. 2015, 29, 4427-4445. [CrossRef]

18. Rahman, M.R.; Shi, Z.H.; Chongfa, C. Assessing regional environmental quality by integrated use of remote sensing, GIS, and spatial multi-criteria evaluation for prioritization of environmental restoration. Environ. Monit. Assess. 2014, 186, 6993-7009. [CrossRef] [PubMed]

19. Saaty, T.L. The Analytic Hierarchy Process: Planning, Priority Setting, Resource Allocation; McGraw-Hill: New York, NY, USA, 1980.

20. Zadeh, L.A. Fuzzy logic = computing with words. IEEE Trans. Fuzzy Syst. 1996, 4, 103-111. [CrossRef]

21. Lee, G.; Jun, K.S.; Chung, E.-S. Robust spatial flood vulnerability assessment for Han River using fuzzy TOPSIS with $\alpha$-cut level set. Expert Syst. Appl. 2014, 41, 644-654. [CrossRef]

22. Lee, M.-J.; Kang, J.E.; Kim, G. Application of fuzzy combination operators to flood vulnerability assessments in Seoul, Korea. Geocarto Int. 2015, 1-24. [CrossRef]

23. Rezaei, F.; Safavi, H.R.; Ahmadi, A. Groundwater vulnerability assessment using fuzzy logic: A case study in the Zayandehrood aquifers, Iran. Environ Manag. 2013, 51, 267-277. [CrossRef] [PubMed]

24. Şener, E.; Şener, Ş. Evaluation of groundwater vulnerability to pollution using fuzzy analytic hierarchy process method. Environ. Earth Sci. 2015, 73, 8405-8424. [CrossRef]

25. Singh, P.K.; Nair, A. Livelihood vulnerability assessment to climate variability and change using fuzzy cognitive mapping approach. Clim. Chang. 2014, 127, 475-491. [CrossRef]

26. Gray, S.R.J.; Gagnon, A.S.; Gray, S.A.; O’Dwyer, B.; O’Mahony, C.; Muir, D.; Devoy, R.J.N.; Falaleeva, M.; Gault, J. Are coastal managers detecting the problem? Assessing stakeholder perception of climate vulnerability using Fuzzy Cognitive Mapping. Ocean Coast. Manag. 2014, 94, 74-89. [CrossRef] 
27. Navas, J.M.; Telfer, T.C.; Ross, L.G. Spatial modeling of environmental vulnerability of marine finfish aquaculture using GIS-based neuro-fuzzy techniques. Mar. Pollut. Bull. 2011, 62, 1786-1799. [CrossRef] [PubMed]

28. Talebian, A.; Shafahi, Y. The treatment of uncertainty in the dynamic origin-destination estimation problem using a fuzzy approach. Trans. Plan. Technol. 2015, 38, 795-815. [CrossRef]

29. Teh, L.C.; Teh, L.S. A fuzzy logic approach to marine spatial management. Environ. Manag. 2011, 47, 536-545. [CrossRef] [PubMed]

30. Zhang, J.; Wang, K.; Chen, X.; Zhu, W. Combining a fuzzy matter-element model with a geographic information system in eco-environmental sensitivity and distribution of land use planning. Int. J. Environ. Res. Public Health 2011, 8, 1206-1221. [CrossRef] [PubMed]

31. Sivanandam, S.; Sumathi, S.; Deepa, S. Introduction to Fuzzy Logic Using Matlab; Springer: Berlin, Germany, 2007; Volume 1.

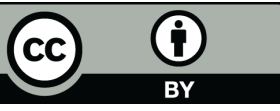

(C) 2017 by the authors. Licensee MDPI, Basel, Switzerland. This article is an open access article distributed under the terms and conditions of the Creative Commons Attribution (CC BY) license (http://creativecommons.org/licenses/by/4.0/). 